\title{
AC 2011-62: INTEGRATION OF NUMERICAL AND EXPERIMENTAL STUDIES IN A HEAT TRANSFER COURSE TO ENHANCE STUDENTS' CONCEPT
}

\section{N.M. A HOSSAIN, Eastern Washington University}

Dr. Hossain is an assistant professor in the Department of Engineering and Design at Eastern Washington University, Cheney. His research interests involve the computational and experimental analysis of lightweight space structures and composite materials. Dr. Hossain received M.S. and Ph.D. degrees in Materials Engineering and Science from South Dakota School of Mines and Technology, Rapid City, South Dakota.

Martin Weiser is an Assistant Professor in the Engineering and Design Department at Eastern Washington University. He earned his BS in Ceramic Engineering from the Ohio State University and his MS and $\mathrm{PhD}$ in Materials Science and Mineral Engineering from the University of California at Berkeley. He then joined the Mechanical Engineering department at the University of New Mexico where he taught Materials Science, Thermodynamics, Manufacturing Engineering, and Technical Communication. Martin then joined Johnson Matthey Electronics/Honeywell Electronic Materials where he held positions in Technical Service, Product Management, Six Sigma, and Research \& Development. He is inventor on a dozen patents and patent applications and has published over 30 papers and book chapters on topics including ceramic processing, $\mathrm{Pb}$-free solder development, experimental design, and biomechanics.

Dr. Saad received his high school education in Lebanon. His BS and MS were received from Marquette University in Milwaukee, WI. The emphasis of his master's dissertation was on a finite element analysis of a solder joint under thermal loading. Dr. Saad received his PhD from Washington State University in Pullman, WA. His research focused on the energy dissipation function of an abrasive water jet cutting through steel. In addition to this, Dr. Saad has taught a vast number of engineering classes at many institutions and is currently teaching, among other classes, Statics, Strength of Materials, Dynamics and Senior Capstone at Eastern Washington University.

Professor Durfee received his BS and MS degrees in Mechanical Engineering from Brigham Young University. He holds a Professional Engineer certification. Prior to teaching at Eastern Washington University he was a military pilot, an engineering instructor at West Point and an airline pilot. His interests include aerospace, aviation, professional ethics and piano technology.

\section{Martin W. Weiser, Engineering and Design Department, Eastern Washington University}

Martin Weiser earned his BS in Ceramic Engineering from Ohio State University and his MS and PhD in Materials Science and Mineral Engineering from the University of California at Berkeley. He joined the Mechanical Engineering department at the University of New Mexico where he taught Materials Science, Thermodynamics, Manufacturing Engineering, and Technical Communication. His next stop was with Johnson Matthey Electronics/ Honeywell Electronic Materials where he was held positions in Technical Service, Product Management, Six Sigma, and Research \& Development. He joined the Engineering and Design Department at EWU in 2010. He has published over 30 papers and book chapters and is inventor on a dozen patents and patent applications.

Hani S. Saad, Eastern Washingotn University Jason K Durfee, Eastern Washington University

Professor DURFEE received his BS and MS degrees in Mechanical Engineering from Brigham Young University. He holds a Professional Engineer certification. Prior to teaching at Eastern Washington University he was a military pilot, an engineering instructor at West Point and an airline pilot. His interests include aerospace, aviation, professional ethics and piano technology. 


\title{
Integration of Numerical and Experimental Studies in a Heat Transfer Course to Enhance the Students' Understanding
}

\begin{abstract}
The primary objective of a heat transfer course is to provide the fundamental knowledge necessary to understand the behavior of thermal systems. This course provides a detailed calculus-based analysis, including the application of differential equations, of heat transfer through solids, fluids, and vacuum. Convection, conduction, and radiation heat transfer in oneand two dimensional steady and unsteady systems are examined. Covering all of these topics in a one quarter course is very challenging to complete in a satisfactory manner. There is very little time for instructors to incorporate thorough experimental study of each educational item covered in the class. Therefore, the authors use a combination of numerical and experimental studies to strengthen the students' conceptual understanding beyond the classroom lectures. The learning process starts with a one-dimensional heat transfer problem using a straight fin. First, students will learn how to solve for the temperature distribution and heat loss using the standard differential equations. Then, students will solve the same problem numerically using the finite element approach (FEA). In this case, students will solve the problem using both matrix algebra and the ANSYS finite element package. Finally, students will perform the experiment and compare the experimental outcomes with analytical and numerical results. Similar learning strategies are used for heat transfer from a sphere, a cylinder and a more complex shape will be discussed in other papers. Problems will be solved for temperature distribution and heat loss using both the lumped capacitance model and numerical method using ANSYS with final experimental validation. Several parametric analyses, using ANSYS, will also be conducted to extend the students' understanding into more complex systems. The learning methodology is a great experience for students to learn numerous heat transfer concepts in the limited time available in a one quarter course. The purpose of this paper is to explain the details of this teaching methodology and discuss the educational outcomes obtained in our heat transfer curriculum.
\end{abstract}




\section{Introduction}

This paper documents an initial heat transfer project that incorporates analytical, numerical (finite element), and experimental analyses to enhance students' understanding of conduction and convection. Three different heat transfer projects are conducted in the course. These projects are designed to demonstrate the fundamental heat transfer concepts once they have been covered in the lecture. We have found in previous courses that conducting experiments and solving the equations for devices that they can handle increases the students' understanding. We use 3 different methods to solve the equations for 2 reasons, (1) some students relate better to each of the methods and (2) by the time it has been done 3 times most students will finally understand what is being done. This first project deals with a one-dimensional (1D), steady state heat transfer conduction and convection problem, which is solved analytically, numerically and finally experimentally. This is followed by a second and third project that deals with transient heat transfer convection problems, which are solved numerically and experimentally. All three projects are conducted in a one quarter long undergraduate heat transfer course (ME 444). The purpose of these projects is to strengthen the students' understanding of conduction and convection heat transfer through computational methods and corresponding experimental testing beyond the regular class lectures.

Similar project works were previously completed by other educators. Halloran and Doughty ${ }^{1,2}$ combined numerical analysis with experimental testing to strengthen the students' understanding of heat transfer dealing with convection. Besser ${ }^{3}$ used spreadsheets to solve twodimensional (2D) heat transfer problems. Goldstein ${ }^{4}$ also used computational methods to teach several topics in heat transfer courses besides the standard in-class lectures. All of the above mentioned efforts were provided to strengthen the students' understanding in several topics in a heat transfer course.

In our institution, several laboratory experiments are usually conducted besides the regular lectures to enhance the students' understanding of numerous concepts of heat transfer. This is definitely beneficial for our students to get real hands-on experience. However, some experiments might be difficult to perform and time consuming. Additional experimental work to conduct parametric analysis is challenging. Therefore, computational (or numerical) analysis is incorporated besides the regular laboratory experimental work to lessen the burden of experiments, and subsequently strengthen students' understanding.

This paper is organized as follows. Following the introduction, the analytical and numerical solutions for temperature distribution of a 1D fin problem are discussed. The commercially available FEA code ANSYS is used to solve the problem using 1D conduction and convection heat transfer elements. The experimental results are then presented in detail and compared with corresponding numerical solutions. A student survey is provided to gauge the effectiveness of students' learning of the intended course materials.

\section{Solving the Fin Problem: Analytical Approach}

This section presents an analytical approach to determine temperature distribution along a rectangular fin subjected to heat loss through convection. The length, width and thickness of the fin are L, b and t, respectively as shown in Figure 1 below. 


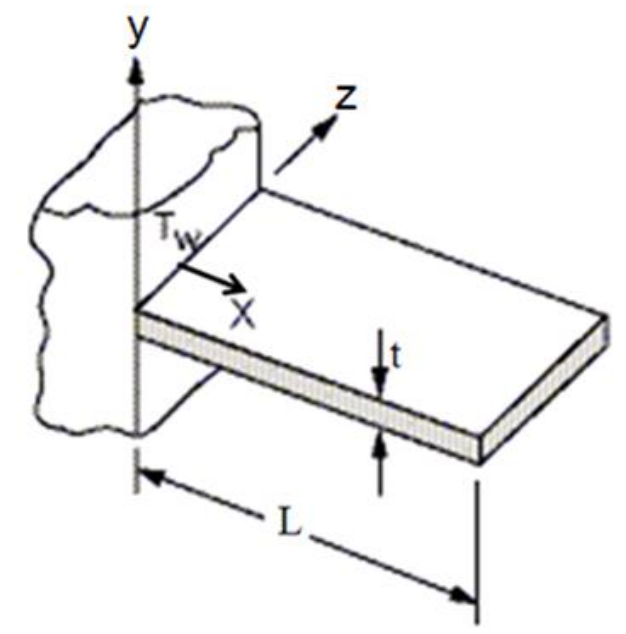

Figure 1: Physical model of a rectangular fin. The figure is taken from ANSYS documentation ${ }^{5}$.

The base of the fin is kept at a constant temperature $T_{\mathrm{w}}$ and the following assumptions are considered to determine the temperature distribution along the length directions.

a) Heat is transferred to the fin via its base due to conduction.

b) Heat is flowing in one dimension only, along the length axis of the fin.

c) No heat is lost from the tip of the fin, only through convection on the sides.

d) The thermal properties of the material remain constant with temperature.

The governing differential equation for this situation is derived in the class and this derivation is summarized here since most texts skip the derivation. Heat conduction in the $\mathrm{x}$ - direction is given by Fourier's Law as

$$
q_{\text {cond }}=-k A \frac{d T}{d x}
$$

The differential heat lost due to convection is given by

$$
q_{\text {conv }}=h P d x\left(T(x)-T_{\infty}\right)
$$

Where $\mathrm{P}$ is the perimeter of a vertical slice of the fin and the area of that slice is Pdx. The first law of thermodynamics states that the total heat flow will be zero which gives

$$
-k A \frac{d T}{d x}+h P d x\left(T(x)-T_{\infty}\right)=0
$$

Dividing by $-\mathrm{kAdx}$ results in

$$
\frac{d^{2} T}{d x^{2}}-\frac{h P}{k A}\left(T(x)-T_{\infty}\right)=0
$$

Since $\mathrm{T}_{\infty}$ is a constant we can rewrite equation 4 as equation 5 which is the form normally presented in most texts.

$$
\frac{d^{2}\left(T(x)-T_{\infty}\right)}{d x^{2}}-\frac{h P}{K A}\left(T(x)-T_{\infty}\right)=0
$$

Where $T(x)$ is the temperature at a distance $\mathrm{x}$ from the base of the fin.

$T_{\infty}$ is the temperature of the environment.

$\mathrm{h}$ is the convection coefficient.

$\mathrm{K}$ is the conductivity of the material.

$\mathrm{A}$ is the area of the base of the fin.

$\mathrm{P}$ is the perimeter of a vertical slice of the fin. 
From Figure 1, students can easily determine the cross sectional area (A) and perimeter (P) as shown in Equations 2 and 3.

$$
\begin{aligned}
& \mathrm{A}=\mathrm{bt} \\
& \mathrm{P}=2(\mathrm{t}+\mathrm{b})
\end{aligned}
$$

In order to simplify equation (1), the term $\theta$ will be defined as

$$
\Theta(x)=T(x)-T_{\infty}
$$

So that equation 5 can be expressed as

$$
\frac{d^{2}(\theta)}{d x^{2}}-\frac{h P}{K A}(\theta)=0
$$

This second order differential equation can be solved by finding the characteristic equation. This equation is obtained by substituting any term of the form $\frac{d^{n}()}{d x^{n}}$ with one of the form $r^{n}$. The resulting quadratic equation can be solved for $r$ and based on the nature of this solution (real, double or complex roots) the solution to the differential equation will be one form of the other. In this case, the characteristic equation becomes

$$
r^{2}-\frac{h P}{K A}=0
$$

The solution is therefore

$$
r= \pm \sqrt{\frac{h P}{K A}}
$$

Since the solution involves two real numbers, the general solution for $\theta(x)$ is

$$
\theta(x)=C_{1} e^{m_{1} x}+C_{2} e^{m_{2} x}
$$

With $C_{1}$ and $C_{2}$ being constants and

$$
m_{1}=+\sqrt{\frac{h P}{K A}}
$$

and

$$
m_{2}=-\sqrt{\frac{h P}{K A}}
$$

When equations 6 and 7 are substituted into equations 13 and 14 the result becomes

$$
m=\sqrt{\frac{2 h(t+b)}{k t b}}
$$

and

$$
m=-\sqrt{\frac{2 h(t+b)}{k t b}}
$$

$C_{1}$ and $C_{2}$ are constants that depend on the boundaries of the problem, i.e., they are specific to the problem at hand. In the case of the fin, one such condition is the fact that at $x=0$, i.e. the base of the fin, the temperature is that of the surface of the body being cooled. Another condition is the fact it was assumed that no heat transfer occurs at the tip of the fin. These two conditions are represented mathematically by the following two equations

$$
\mathrm{T}(0)=T_{\text {base }}
$$

where $T_{\text {base }}$ is the temperature of the surface of the body and

$$
\frac{d T}{d x}=0 \quad \text { at } x=L
$$

Substituting these two equations into equation 11 and simplifying yields the following

$$
\frac{\theta(x)}{\theta_{b a s e}}=\frac{e^{m(b-x)}+e^{-m(b-x)}}{e^{m b}+e^{-m b}}
$$

this result can also be expressed as 


$$
\frac{\theta(x)}{\theta_{b a s e}}=\frac{\cosh (m(b-x)]}{\cosh (m b)}
$$

For the value of $\mathrm{m}$ given by equation 15 , and keeping in mind that $\Theta(\mathrm{x})=\mathrm{T}(\mathrm{x})-\mathrm{T}_{\infty}, \Theta_{\text {base }}=\mathrm{T}_{\text {base}}{ }^{-}$ $T_{\infty}$, the previous result can be expressed as

$$
T(x)=\frac{\cosh (m(b-x))}{\cosh (m b)}\left(T_{b a s e}-T_{\infty}\right)+T_{\infty}
$$

For this particular problem, students measure the following parameters

$$
\begin{aligned}
& \mathrm{h}=30 \mathrm{~W} / \mathrm{m}^{2}{ }^{\mathrm{O}} \mathrm{C} \\
& \mathrm{k}=168 \mathrm{~W} / \mathrm{m}^{\mathrm{O}} \mathrm{C} \\
& \mathrm{t}=1 \mathrm{~mm} \\
& \mathrm{~b}=5 \mathrm{~mm} \\
& \mathrm{~L}=80 \mathrm{~mm} \\
& T_{\text {base }}=100{ }^{\mathrm{O}} \mathrm{C} \\
& T_{\infty}=20^{\circ} \mathrm{C}
\end{aligned}
$$

This yields a value for $m$ equal to

$$
\mathrm{m}=20.7
$$

and the temperature distribution function $\mathrm{T}(\mathrm{x})$ becomes

$$
\mathrm{T}(\mathrm{x})=30.96 \cosh (1.6-20.7 \mathrm{x})
$$

The following graph shows the corresponding values of the temperature at different values for $\mathrm{x}$.

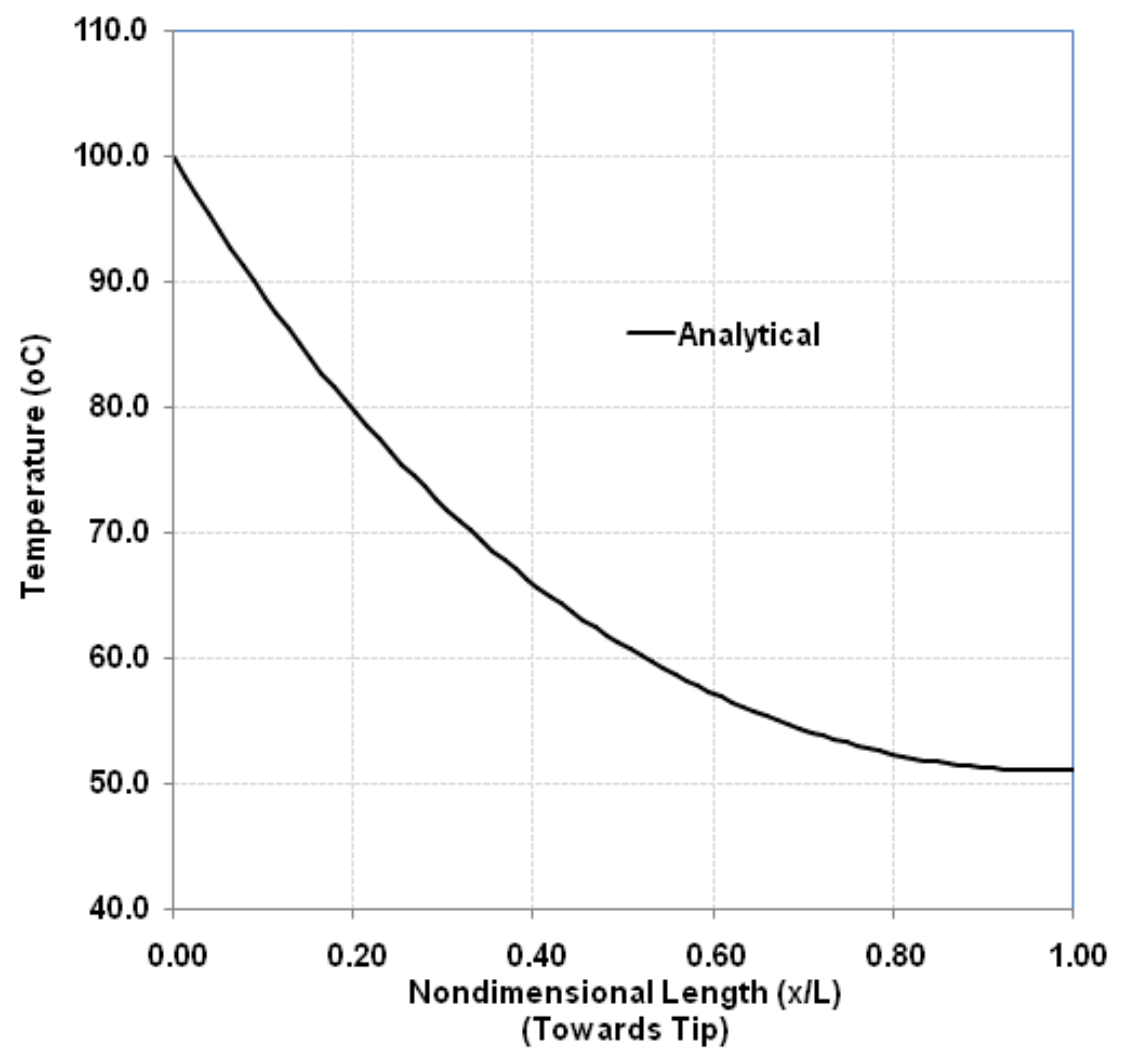

Figure 2: Temperature distribution by analytical method. 


\section{Solving the Fin Problem: Numerical Approach (Matrix Algebra)}

The learning process starts with how to solve for the temperature distribution of a 1D rectangular aluminum fin identical to the one solved previously using the governing differential equations. The fin is considered to be thin enough that the temperature variation along the thickness $(t)$ direction is not significant. As the problem is also considered to be $1 \mathrm{D}$, the temperature distribution along the height direction (-z) is not determined either. The details of this problem are given in Ref [6].

For simplicity, the finite element model for this straight fin consists of four (4) elements and five (5) nodes, as shown in Figure 3(b). Because the cross-sectional area of the fin is relatively small, the heat loss from the tip is neglected. First, students were asked to solve this 1D fin problem using a numerical approach. In this case, students use matrix algebra, which was taught and covered in a previous math class. However, matrix algebra is also reviewed before solving the fin problem numerically.
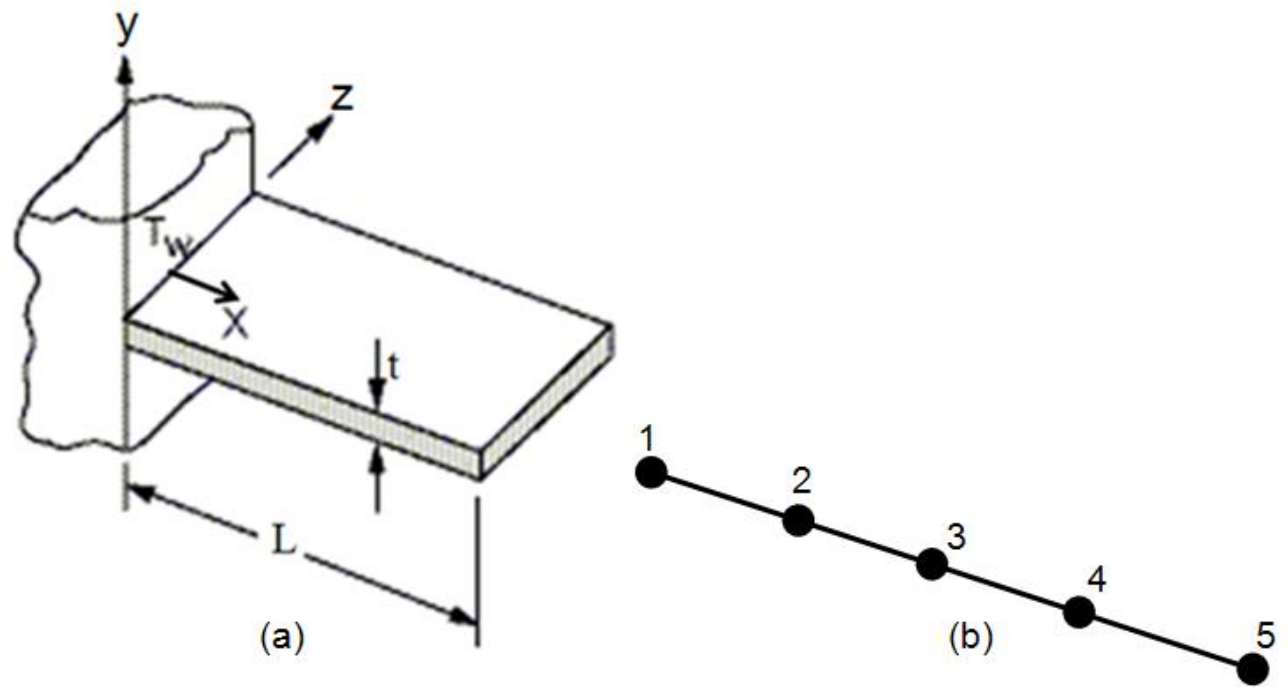

Figure 3: One dimensional fin, (a) Physical model, (b) Finite element model.

The solution process starts with forming conductance (K) and thermal load (F) matrices for each element as shown below.

$$
\begin{aligned}
& {[\mathrm{K}]^{1}=[\mathrm{K}]^{2}=[\mathrm{K}]^{3}=[\mathrm{K}]^{4}=\left\{\frac{k A}{l}\left[\begin{array}{cc}
1 & -1 \\
-1 & 1
\end{array}\right]\right\}} \\
& \{\mathrm{F}\}^{1}=\{\mathrm{F}\}^{2}=\{\mathrm{F}\}^{3}=\{\mathrm{F}\}^{4}=\frac{h p l T_{f}}{2}\left\{\begin{array}{l}
1 \\
1
\end{array}\right\}
\end{aligned}
$$

where $A, l, p, T_{f}$ represent cross-sectional area, length of each element, perimeter and bulk temperature, respectively. Students usually struggle to correlate the elemental conductance and load matrices with corresponding node numbers so Figure 4 is used to explain this critical issue. Students learn that the conductance and thermal load matrices for element \# 1 are associated with nodes 1 and 2. Similarly, the matrices for element \# 2 are associated with nodes 2 and 3, and so on as shown in the Figure 4. Students generally grasp this critical concept quickly. The 
conductance and thermal load matrices are formed for each individual element and then the students are asked to form the global matrices as shown in Figure 5.

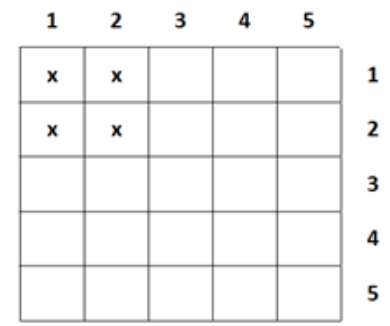

(a)

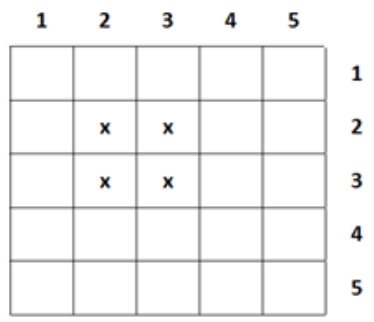

(b)

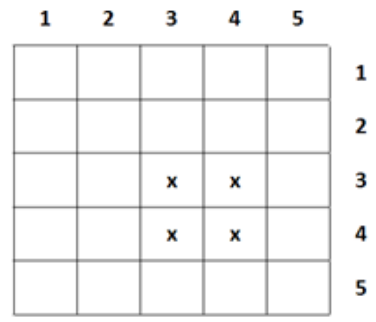

(c)

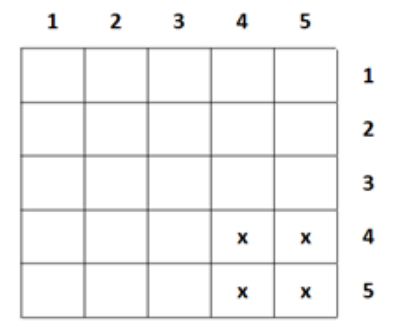

(d)

Figure 4: Correlation of elemental conductance matrix with corresponding nodes. (a) Element \# 1, (b) Element \# 2, (c) Element \# 3, and (d) Element \# 4.

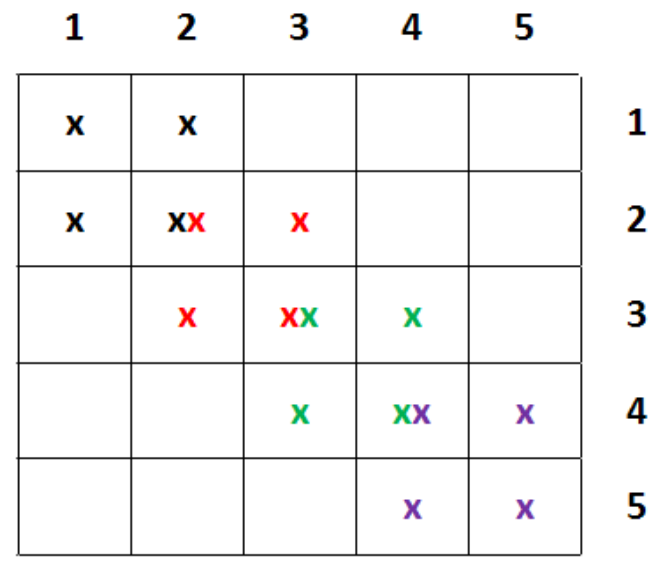

Figure 5: Illustration of global conductance matrix.

The global conductance $[\mathrm{K}]^{\mathrm{G}}$ and load $\{\mathrm{F}\}^{\mathrm{G}}$ matrices can then be transformed into into the final set of linear equations:

$$
\left\{\begin{array}{ccccc}
K_{11} & K_{12} & 0 & 0 & 0 \\
K_{21} & K_{22} & K_{23} & 0 & 0 \\
0 & K_{32} & K_{33} & K_{34} & 0 \\
0 & 0 & K_{43} & K_{44} & K_{45} \\
0 & 0 & 0 & K_{54} & K_{55}
\end{array}\right] *\left\{\begin{array}{l}
T_{1} \\
T_{2} \\
T_{3} \\
T_{4} \\
T_{5}
\end{array}\right\}=\left\{\begin{array}{l}
F_{11} \\
F_{21} \\
F_{31} \\
F_{41} \\
F_{51}
\end{array}\right\}
$$

At this point, students are asked to assign boundary conditions and make necessary changes for the conductance $[\mathrm{K}]^{\mathrm{G}}$ and load $\{\mathrm{F}\}^{\mathrm{G}}$ matrices. Every node has only one degree of freedom (DOF), which is temperature (T). Therefore the boundary condition is $\mathrm{T}_{1}=100{ }^{\circ} \mathrm{C}$. Students are also taught matrix multiplication and they are now able to understand the following change to ensure the desired temperature $\mathrm{T}_{1}$. 


$$
\left\{\begin{array}{ccccc}
1 & 0 & 0 & 0 & 0 \\
K_{21} & K_{22} & K_{23} & 0 & 0 \\
0 & K_{32} & K_{33} & K_{34} & 0 \\
0 & 0 & K_{43} & K_{44} & K_{45} \\
0 & 0 & 0 & K_{54} & K_{55}
\end{array}\right] *\left\{\begin{array}{l}
T_{1} \\
T_{2} \\
T_{3} \\
T_{4} \\
T_{5}
\end{array}\right\}=\left\{\begin{array}{l}
100 \\
F_{21} \\
F_{31} \\
F_{41} \\
F_{51}
\end{array}\right\}
$$

Using the numerical values for global conductance and load matrices, and solving the matrix, students are finally able to obtain the nodal temperatures as shown below.

$$
\left\{\begin{array}{l}
T_{1} \\
T_{2} \\
T_{3} \\
T_{4} \\
T_{5}
\end{array}\right\}=\left\{\begin{array}{c}
100 \\
75.03 \\
59.79 \\
51.56 \\
48.90
\end{array}\right\}
$$

The temperature distribution obtained by matrix algebra is then compared with the analytical solution as shown in Figure 6.

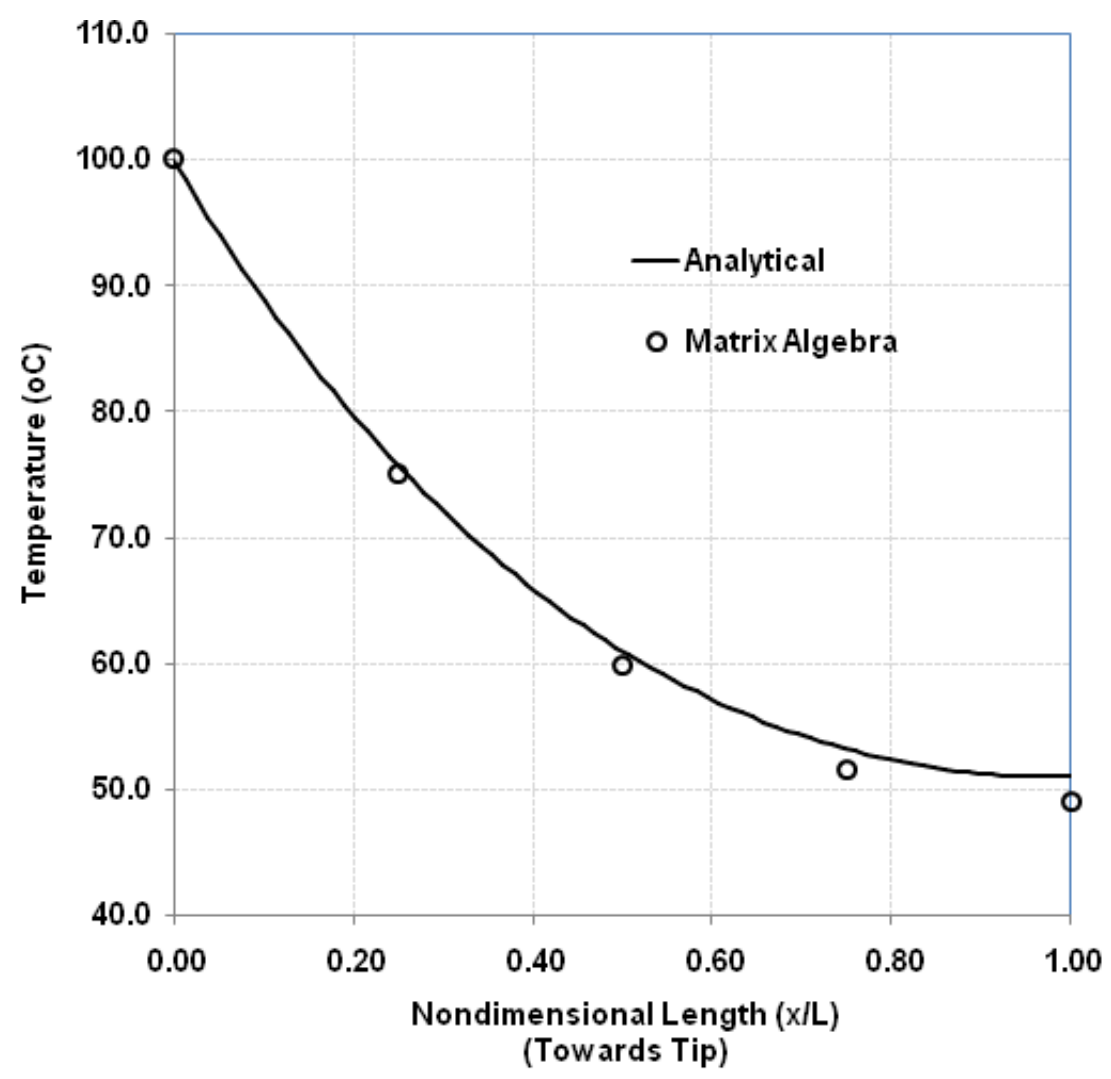

Figure 6: Comparison of temperature distribution between analytical and matrix algebra. 


\section{Solving the Fin Problem: Numerical Approach (ANSYS)}

Finite element analysis (FEA) is a numerical technique that is used to solve complex engineering problems. FEA involves computer model of a design that is loaded and analyzed for specific input conditions. One of the objectives of our Heat Transfer course is to provide some basic knowledge of finite element methods to our students for solving heat transfer problems.

After solving the fin problem analytically, students were then asked to solve the same problem using ANSYS. Students used the one dimensional conduction (Link 32) and convection (Link 34) thermal elements. LINK32 and LINK34 are uniaxial elements consisting of two nodes. Both elements have a single degree of freedom, temperature, at each node point. The conduction element is defined by two nodes, a cross-sectional area, and the material properties. The convection element is defined by two nodes, a convection surface area, and a film coefficient.

The ANSYS analysis is straight forward. First, the element types are defined with all required information. Second, material properties associated with conduction and convection heat transfer are defined. Then the representative FEA model is created according to the geometry and dimension as shown in Figure 3(b). Boundary conditions are assigned representing the wall and bulk temperature. Finally, the FEA model is solved and nodal temperatures are obtained. The ANSYS output using 1D conduction and convection elements are found to match closely with the solution obtained by matrix algebra and analytical solutions as shown in Figure 7.

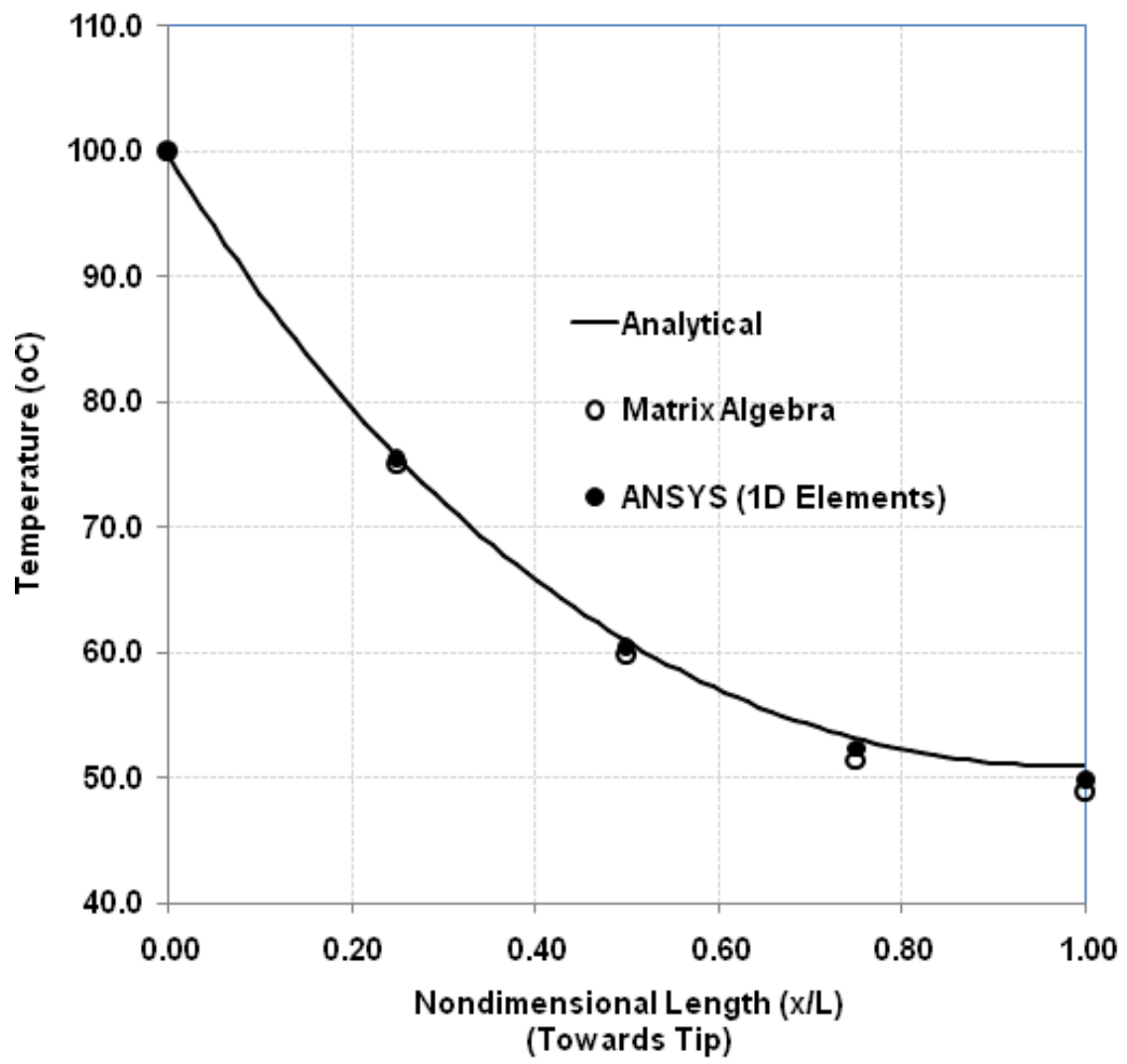

Figure 7: Comparison of temperature distribution between ANSYS (1D Elements), matrix algebra and analytical solutions. 


\section{Solving Fin Problem: Experimental Approach}

The temperature distribution along the fin modeled using the analytical and numerical approaches above was measured experimentally. The fin was machined from a block of 6061-T6 aluminum alloy so that it protruded $85 \mathrm{~mm}$ from a $50 \mathrm{~mm}$ square by $25 \mathrm{~mm}$ thick base. A cartridge heater was inserted into a hole drilled in the base and $5 \mathrm{~mm}$ of low density insulation was applied to the face and sides of the base so that the heat flow would be 1-dimensional along the fin. Small holes were drilled into the face of the fin along the center line at the five positions described earlier and 30 gauge type-K thermocouples were glued into the holes using thermally conductive, but electrically isolative epoxy.

The cartridge heater was powered by a rheostat so that the temperature at the base of the fin could be adjusted to $100^{\circ} \mathrm{C}$ by control of the voltage supplied to the cartridge heater. The temperature of each location along the fin was monitored until the students in each lab group deemed that the fin had reached thermal equilibrium. The groups were intentionally given minimal instruction regarding what constituted thermal equilibrium and the conditions to be maintained around the fin although they were told the rheostat setting that had been previously used to obtain $100^{\circ} \mathrm{C}$ at the fin root.

As expected each student group had a different interpretation how to control the environment around the fin and of thermal equilibrium. In addition, the starting temperature of the fin system was generally higher for groups that conducted their observations later in the lab session so it would appear to reach thermal equilibrium faster. The results from a typical set of three lab groups are compared and shown in Figure 8. The average temperature distribution of the fin measured by experiment is then compared with analytical and numerical solutions as shown in Figure 9. Overall there is quite good agreement between the methods although the experimental results for the fin tip tend to be lower than in the models. This is expected due to the heat flow from the tip that is not included the models. 


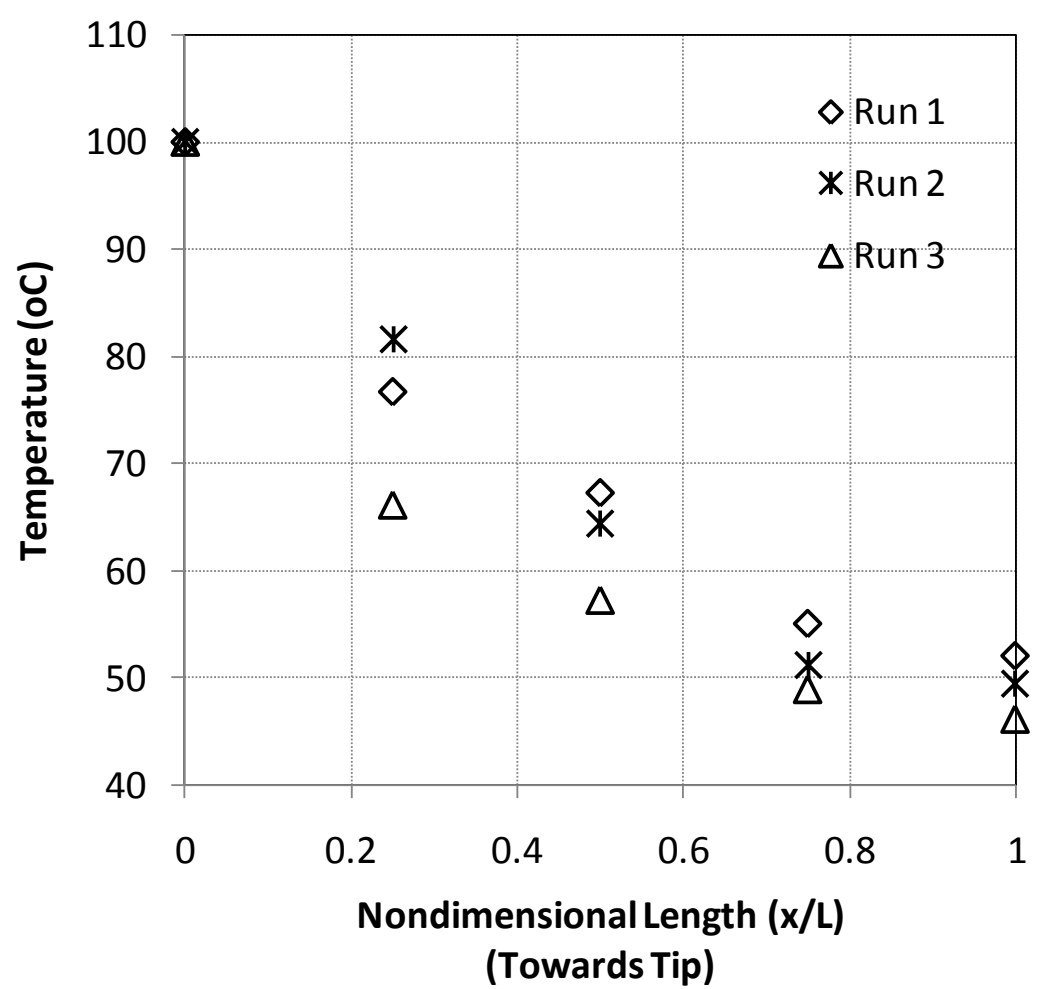

Figure 8: Temperature distribution of fin measured by experiment.

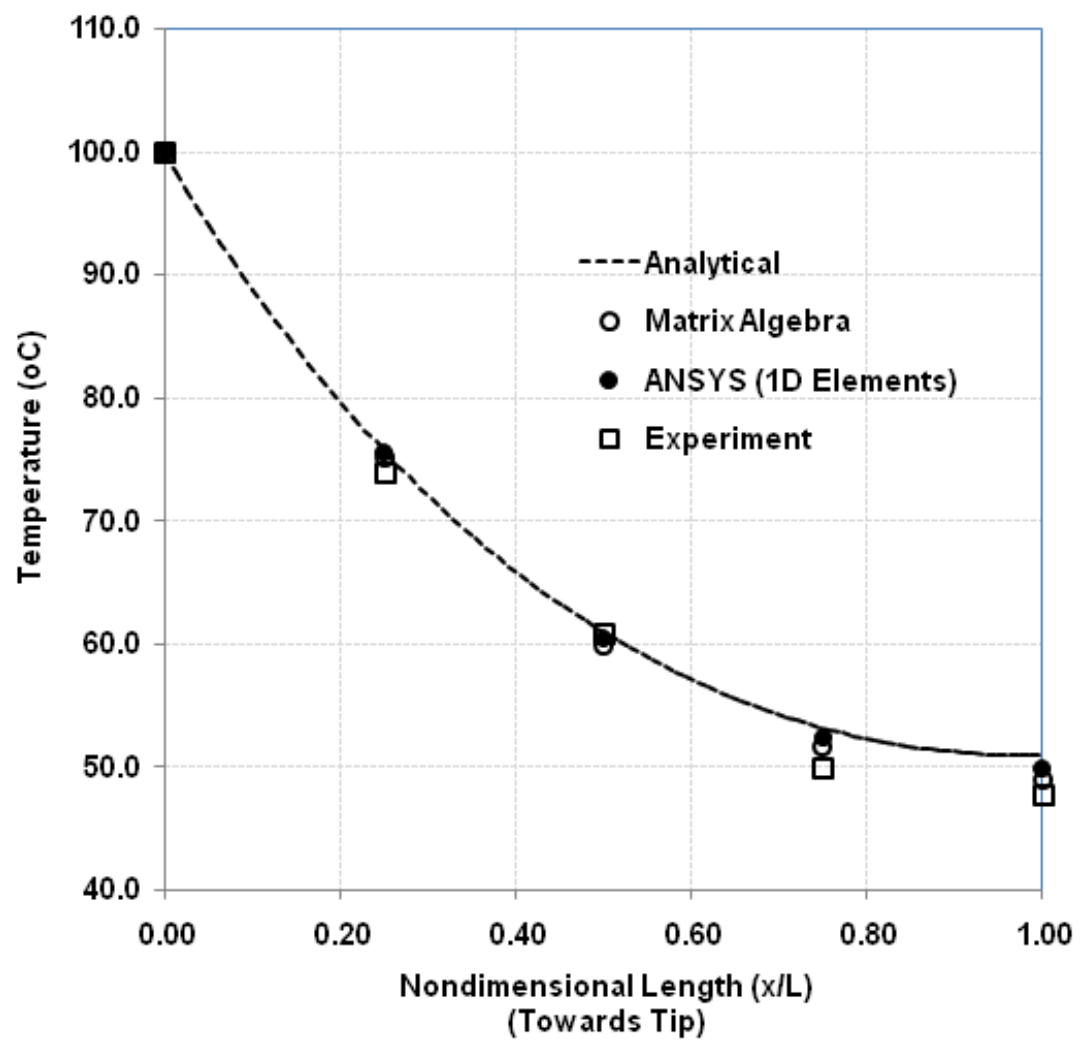

Figure 9: Comparison of temperature distribution of fin problem between analytical, matrix algebra, ANSYS and experimental solutions. 


\section{Student Survey}

Upon completion the analytical, numerical and experimental measurements of temperature distribution of the 1D fin, a student survey is conducted. This survey evaluates the effectiveness of this teaching methodology to enhance the students' understanding on several concepts of heat transfer. Several questions will be asked, as listed below, and students' response will be studied to improve the teaching methodology.

Question \# 1:

Did use of the different methodologies (analytical, numerical, and experimental) to measure the temperature distribution in the 1D fin help increase your understanding of heat transfer?

Question \# 2:

Which method (analytical, numerical, experimental) do you feel was most valuable to increase your understanding of heat transfer? Why?

Question \# 3:

Which method (analytical, numerical, experimental) do you feel was least valuable to increase your understanding of heat transfer? Why?

Question \# 4:

What suggestions do you have to improve this exercise to increase student understanding of conductive/convective heat transfer?

Question \# 5:

If you are given a real heat sink (several fins like the one used in this exercise) which method would you use to evaluate the performance? Why?

\section{Conclusions}

Students are introduced to three different ways to evaluate heat transfer from a fin subjected to 1dimensional heat flow and convective heat transfer to the environment. The progression from the analytical solution to the numeric solution and finally experimental measurement of the temperature profile builds confidence in their ability to use the different tools. The results matched very well between the analytical, matrix and FEA methods which shows the students that such problems can be solved in multiple ways. In addition, it builds confidence in the use of numeric methods for more complex geometries that cannot be solved analytically. The variability of the experimental results and the close, but inexact match to the models demonstrates that the models are just that - models of real world behavior that are only as good as the assumptions used in building them. The survey outcomes collected from students including their feedback will be studied further to improve this exercise to increase the students' understanding of heat transfer. 


\section{Bibliography}

1. T.A. Doughty, and O'Halloran, S.P., "A Cross Curricular Numerical and Experimental Study in Heat Transfer," 2010 ASEE Annual Conference and Exposition, 2009, American Society of Engineering Education.

2. O'Halloran, S.P. and T.A. Doughty, "Integration of Numerical Analysis and Experimental Testing Involving Heat Transfer for a Small Heated Cylinder During Cooling," 2009 ASEE Annual Conference and Exposition, 2009, American Society of Engineering Education.

3. Besser, R.S., "Spreadsheet Solutions to Two-Dimensional Heat Transfer Problems," Chemical Engineering Education, Vol. 36, No. 2, 2002, pp. 160-165.

4. Goldstein, A.S., "A Computational Model for Teaching Free Convection," Chemical Engineering Education, Vol. 38, No. 4, 2004, pp. 272-278.

5. ANSYS Documentation, version 11

6. Moaveni, S., "Finite Element Analysis - Theory and Application with ANSYS," Edition -3, pp. 286-290 